\title{
A Visibilidade da Política Nacional de Humanização da Saúde no Campo da Produção do Conhecimento: Identificando Suas Possibilidades e Limites Pela Pesquisa Documental
}

\author{
Noronha, Valéria dos Santos; Oliveira, Miranda Marivan dos Santos \\ Universidade Federal do Recôncavo da Bahia — valerianoronha@gmail.com
}

Introdução o presente trabalho emerge a partir de inquietações existentes relacionadas à visibilidade da Política Nacional de Humanização da Saúde nos estudos científicos, principalmente no campo da formulação e gestão da política. Acreditamos que seja fundamental a ampliação de pesquisas para maiores aprofundamentos sobre a implementação, sua funcionalidade e perspectivas da Política Nacional de Humanização da Saúde nas diversas regiões do país, especialmente no Nordeste, território no qual estamos vinculados e desenvolvendo investigações na área da saúde pública. Objetivos Conhecer por meio de um estudo exploratório as produções científicas relacionadas ao campo da humanização da saúde no sentido de identificar a sua visibilidade, especialmente no que tange à formulação e gestão da política. Métodos Estão sendo utilizadas as pesquisas bibliográfica e documental com levantamento e consulta aos principais bancos de dados - SCIELO e CAPES feitas a partir do segundo semestre de 2013. para as pesquisas foram considerados três grupos de descritores. 0 primeiro grupo se ocupou de maneira mais extensa de palavras ou expressões que estivessem relacionadas ao tema da "Humanização"; o segundo grupo considerou apenas os descritores "Gestão e Humanização"; e a terceira e última pesquisa adotou os descritores "Formulação e Humanização". Resultados: nas base de dados do SCIELO e da CAPES, a discussão sobre assistência à saúde e humanização do parto ganham maior destaque. em especial, no que diz respeito à Política de Humanização, o portal da CAPES demonstra destaque, assim como no SCIELO, para estudos que possuem como temática os princípios e diretrizes da política. Aqueles referentes aos processos de implementação também são relevantes. Quanto à gestão e principalmente à formulação da $\mathrm{PNH}$, a referente pesquisa (ainda em processo de finalização) já demonstra a ausência de maiores estudos e aprofundamentos vinculados à produção do conhecimento no campo da elaboração da política. Conclusões: por meio da pesquisa identificamos a necessidade de ampliar e fortalecer os estudos principalmente na esfera da formulação da Política Nacional de Humanização da Saúde, conhecer seu contexto histórico, seus desdobramentos e suas interfaces políticas nas principais regiões brasileiras, reconhecendo que o estabelecimento de redes de cooperação técnica e de pesquisa, maior estímulo, investimentos e fomento no âmbito da investigação científica são fundamentais para fortalecer as produções já existentes e garantir a visibilidade de pesquisas e experiências de humanização na saúde.

Noronha, Valéria dos Santos; Oliveira, Miranda Marivan dos Santos. A Visibilidade da Política Nacional de Humanização da Saúde no Campo da Produção do Conhecimento: Identificando Suas Possibilidades e Limites Pela Pesquisa Documental. In: Anais do Congresso Internacional de Humanidades \& Humanização em Saúde [= Blucher Medical Proceedings, num.2, vol.1]. São Paulo: Editora Blucher, 2014. ISSN 2357-7282

DOI 10.5151/medpro-cihhs-10214 